\title{
The importance of a surface organic layer in simulating permafrost thermal and carbon dynamics
}

\author{
Elchin Jafarov ${ }^{1}$ and Kevin Schaefer ${ }^{2}$ \\ ${ }^{1}$ Institute of Arctic and Alpine Research, University of Colorado at Boulder, Boulder, CO 80309, USA \\ ${ }^{2}$ National Snow and Ice Data Center, Cooperative Institute for Research in Environmental Sciences, University of Colorado at \\ Boulder, Boulder, CO 80309, USA
}

Correspondence to: Elchin Jafarov (elchin.jafarov@colorado.edu)

Received: 4 May 2015 - Published in The Cryosphere Discuss.: 12 June 2015

Revised: 3 February 2016 - Accepted: 10 February 2016 - Published: 1 March 2016

\begin{abstract}
Permafrost-affected soils contain twice as much carbon as currently exists in the atmosphere. Studies show that warming of the perennially frozen ground could initiate significant release of the frozen soil carbon into the atmosphere. Initializing the frozen permafrost carbon with the observed soil carbon distribution from the Northern Circumpolar Soil Carbon Database reduces the uncertainty associated with the modeling of the permafrost carbon feedback. To improve permafrost thermal and carbon dynamics we implemented a dynamic surface organic layer with vertical carbon redistribution, and introduced dynamic root growth controlled by active layer thickness, which improved soil carbon exchange between frozen and thawed pools. These changes increased the initial amount of simulated frozen carbon from 313 to $560 \mathrm{GtC}$, consistent with observed frozen carbon stocks, and increased the spatial correlation of the simulated and observed distribution of frozen carbon from 0.12 to 0.63 .
\end{abstract}

\section{Introduction}

Warming of the global climate will lead to widespread permafrost thaw and degradation with impacts on ecosystems, infrastructure, and emissions that amplify climate warming (Oberman, 2008; Callaghan et al., 2011; Schuur et al., 2015). Permafrost-affected soils in the high northern latitudes contain $1300 \pm 200 \mathrm{Gt}$ of carbon, where $\sim 800 \mathrm{GtC}$ is preserved frozen in permafrost with $\sim 550 \mathrm{GtC}$ in the top $3 \mathrm{~m}$ of soil (Tarnocai et al., 2009; Hugelius et al., 2014). As permafrost thaws, organic matter frozen within permafrost will thaw and decay, which will initiate the permafrost carbon feedback, releasing an estimated $120 \pm 85 \mathrm{Gt}$ of carbon emissions by 2100 (Schaefer et al., 2014). The wide range of estimates of carbon emissions from thawing permafrost depends, to a large extent, on the ability of models to simulate present permafrost extent (Brown et al., 1997). For example, the simulated permafrost in some models is significantly more sensitive to thaw, with corresponding larger estimates of carbon emissions (Koven et al., 2013). Narrowing the uncertainty in estimated carbon emissions requires improvements in how land surface models (LSMs) represent permafrost thermal and carbon dynamics.

The active layer in permafrost regions is the surficial soil layer overlying the permafrost, which undergoes seasonal freeze-thaw cycles. Active layer thickness (ALT) is the maximum depth of thaw at the end of summer. LSMs used to estimate emissions from thawing permafrost typically assume that the frozen carbon is located in the upper permafrost above $3 \mathrm{~m}$ depth and below the maximum ALT (Koven et al., 2011; Schaefer et al., 2011; MacDougall et al., 2012). Thus, the simulated ALT determines the volume of permafrost in the top $3 \mathrm{~m}$ of soil, and thus the initial amount of frozen carbon. Consequently, any biases in the simulated ALT will influence the initial amount of frozen carbon, even if different models initialize the frozen carbon in the same way. In addition, the same thermal biases that lead to deeper simulated active layers lead to warmer soil temperatures, making the simulated permafrost more vulnerable to thaw and resulting in higher emissions estimates (Koven et al., 2013).

The surface organic layer (SOL) is the surface soil layer of nearly pure organic matter that exerts a huge influence on 
the thermodynamics of the active layer. The organic layer thickness (OLT) usually varies between 5 and $30 \mathrm{~cm}$, depending on a balance between the litter accumulation rate relative to the organic matter decomposition rate (Yi et al., 2009; Johnstone et al., 2010). A recent model intercomparison study shows that LSMs need more realistic surface processes such as an SOL and better representations of subsoil thermal dynamics (Ekici et al., 2015). The low thermal conductivity of the SOL makes it an effective insulator, decreasing the heat exchange between permafrost and the atmosphere (Rinke et al., 2008). The effect of the SOL has been well presented in several modeling studies. For example, Lawrence and Slater (2008) showed that soil organic matter affects the permafrost thermal state in the Community Land Model, and Jafarov et al. (2012) discussed the effect of the SOL in the regional modeling study for Alaska, United States. Recently, Chadburn et al. (2015a, b) incorporated an SOL in the Joint UK Land Environment Simulator (JULES) model to illustrate its influence on ALT and ground temperatures both at a site-specific study in Siberia, Russia, and globally. In essence, the soil temperatures and ALT decrease as the OLT increases. Consequently, how (or if) LSMs represent the SOL in the simulated soil thermodynamics will simultaneously determine the initial amount of frozen permafrost carbon and the vulnerability of the simulated permafrost to thaw.

In this study we improved present-day frozen carbon stocks in the Simple Biosphere/Carnegie-Ames-Stanford Approach (SiBCASA) model to reduce biases in initial permafrost carbon stocks and improve the dynamics of future permafrost carbon release. To achieve this we introduce three improvements into the SiBCASA model: (1) improve the soil thermal dynamics and ALT, (2) improve soil carbon dynamics and build-up of carbon stocks in soil, and (3) initialize the older, frozen carbon using observed circumpolar soil carbon (Hugelius et al., 2014).

\section{Methods}

We used the SiBCASA model (Schaefer et al., 2008) to evaluate current soil carbon stocks in permafrost affected soils. SiBCASA has fully integrated water, energy, and carbon cycles and computes surface energy and carbon fluxes at $10 \mathrm{~min}$ time steps. SiBCASA predicts the moisture content, temperature, and carbon content of the canopy, canopy air space, and soil (Sellers et al., 1996; Vidale and Stockli, 2005). To calculate plant photosynthesis, the model uses a modified BallBerry stomatal conductance model (Ball, 1998; Collatz et al., 1991) coupled to a C3 enzyme kinetic model (Farquhar et al., 1980) and a C4 photosynthesis model (Collatz et al., 1992). It predicts soil organic matter, surface litter, and live biomass (leaves, roots, and wood) in a system of 13 prognostic carbon pools as a function of soil depth (Schaefer et al., 2008). The model biogeochemistry does not account for disturbances, such as fire, and does not include a nitrogen cycle. SiBCASA separately calculates respiration losses due to microbial decay (heterotrophic respiration) and plant growth (autotrophic respiration).

SiBCASA uses a fully coupled soil temperature and hydrology model with explicit treatment of frozen soil water originally from the Community Climate System Model, version 2.0 (Bonan, 1996; Oleson et al., 2004). To improve simulated soil temperatures and permafrost dynamics, Schaefer et al. (2009) increased the total soil depth to $15 \mathrm{~m}$ and added the effects of soil organic matter on soil physical properties. Simulated snow density and depth, and thus thermal conductivity, significantly influence simulated permafrost dynamics, so Schaefer et al. (2009) added the effects of depth hoar and wind compaction on simulated snow density and depth. Recent model developments include accounting for substrate availability in frozen soil biogeochemistry (Schaefer and Jafarov, 2015).

We spun SiBCASA up to steady-state initial conditions using an input weather data set from the modified Climatic Research Unit National Center for Environmental Prediction (CRUNCEP) $^{1}$ (Wei et al., 2014) for the entire permafrost domain in the Northern Hemisphere (Brown et al., 1997). CRUNCEP is modeled weather data at $0.5 \times 0.5$ degree latitude and longitude resolution, optimally consistent with a broad array of observations. The CRUNCEP data set used in this study spans 110 years, from 1901 to 2010 . We selected the first 30 years from the CRUNCEP data set (1901 to 1931) and randomly distributed them over 900 years. To run our simulations we used JANUS High Performance Computing (HPC) Center at the University of Colorado at Boulder. The 900 -year time span was chosen in order to make optimal use of the computational time, which allowed us to finish one spin-up simulation on JANUS HPC without interruptions.

\subsection{Frozen carbon initialization}

We initialized the frozen carbon stocks using the Northern Circumpolar Soil Carbon Dataset version 2 (NCSCDv2) (Hugelius et al., 2014). The NCSCDv2 includes soil carbon density maps in permafrost-affected soils available at several spatial resolutions ranging from 0.012 to $1^{\circ}$. The data set consists of spatially extrapolated soil carbon data from more than 1700 soil core samples. We used three layers from the NCSCDv2 data set, each $1 \mathrm{~m}$ in depth, distributed between ground surface and $3 \mathrm{~m}$ depth.

We placed the frozen carbon within the top $3 \mathrm{~m}$ of simulated permafrost, ignoring deltaic and loess deposits that are known to extend well beyond $3 \mathrm{~m}$ of depth (Hugelius et al., 2014). The bottom of the permafrost carbon layer is fixed at $3 \mathrm{~m}$, while the top varies spatially, depending on the simulated ALT during the spin-up run. We initialized the per-

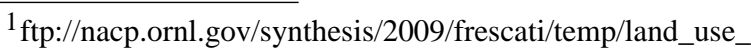
change/original/readme.htm
} 
mafrost carbon by assigning carbon from the NCSCDv2 to the frozen soil carbon pools below the maximum thaw depth. These frozen pools remained inactive until the layer thaws.

We initialized frozen carbon between the permafrost table and $3 \mathrm{~m}$ depth using two scenarios: (1) spatially uniform distribution of the frozen carbon throughout the permafrost domain (Schaefer et al., 2011), and (2) observed distribution of the frozen carbon according to the NCSCDv2. It is important to know the "stable" depth of the active layer before initializing frozen carbon. We ran the model for several years in order to calculate ALT, and then initialized frozen carbon below the maximum calculated ALT. The frozen carbon was initialized only once after the first spin-up simulation. For the next simulation we used the previously calculated permafrost carbon. We defined an equilibrium point when changes in overall permafrost carbon were negligible or almost zero.

The total initial frozen carbon in each soil layer between the permafrost table and $3 \mathrm{~m}$ is

$C_{\mathrm{fr}}^{i}=\rho_{\mathrm{c}} \Delta z_{i}$,

where $C_{\mathrm{fr}}^{i}$ is the total permafrost carbon within the $i$ th soil layer, $\rho_{\mathrm{c}}$ is the permafrost carbon density, and $\Delta z_{i}$ is the thickness of the $i$ th soil layer in the model. For the uniform permafrost carbon distribution, spatially and vertically uniform $\rho_{\mathrm{c}}$ of $21 \mathrm{~kg} \mathrm{C} \mathrm{m}^{-3}$ (Schaefer et al., 2011). For the observed distribution from the NCSCDv2, $\rho_{\mathrm{c}}$ varies both with location and depth (Hugelius et al., 2013).

The permafrost carbon in each layer is divided between slow $\left(C_{\text {slow }}\right)$, metabolic $\left(C_{\text {met }}\right)$, and structural $\left(C_{\text {str }}\right)$ soil carbon pools as follows:

$C_{\text {slow }}^{i}=0.8 C_{\mathrm{fr}}^{i}$

$C_{\text {met }}^{i}=0.2 f_{\text {root } 2 \text { meet }} C_{\mathrm{fr}}^{i}$

$C_{\mathrm{str}}^{i}=0.2 f_{\text {root } 2 \mathrm{strt}} C_{\mathrm{fr}}^{i}$,

where $f_{\text {root2met }}$ and $f_{\text {root2strt }}$ are the simulated fractions of root pool losses to the soil metabolic and structural pools respectively (Schaefer et al., 2008). The nominal turnover time is 5 years for the slow pool, 76 days for the structural pool, and 20 days for the metabolic pool. Schaefer et al. (2011) state a $5 \%$ loss to the metabolic pool and a $15 \%$ loss to the structural pool based on observed values in Dutta et al. (2006). The simulated fractions are actually $5.6 \%$ to the metabolic pool and $14.4 \%$ to the structural pool. We found it encouraging that the numbers calculated with the SiBCASA metabolic fractions resulted in numbers that are close to the observed values in Dutta et al. (2006).

\subsection{Dynamic SOL}

We modified SiBCASA to include a dynamic SOL by incorporating the vertical redistribution of organic material associated with soil accumulation. SiBCASA calculates the soil physical properties as a weighted average of those for organic matter, mineral soil, ice, and water (Schaefer et al., 2009). The physical properties include soil porosity, hydraulic conductivity, heat capacity, thermal conductivity, and matric potential. The model calculates the organic fraction used in the weighted mean as the ratio of simulated carbon density to the density of pure organic matter. The model does not account for the compression of organic matter. Since the prognostic soil carbon pools vary with depth and time, the organic fraction and the physical properties all vary with time and depth. We only summarized these calculations here since the calculations are covered in detail in Schaefer et al. (2009).

As live, above-ground biomass in the model dies, carbon is transferred into the first layer as litter. Without the vertical redistribution we describe here to create a surface organic layer, the top layer of the model tended to accumulate carbon in excess of that expected for pure organic matter. To allow vertical movement and build up a SOL, we placed a maximum limit on the amount of organic material that each soil layer can hold. When the simulated carbon content exceeds this threshold, the excess carbon is transferred to the layer below. This is a simplified version of the Koven et al. (2009) carbon diffusion model, which accounts for all sedimentation and cryoturbation processes. This simplified model is better suited for our application because we wanted to focus only to the buildup of a SOL.

We calculate the maximum allowed carbon content per soil layer, $C_{\max }$, as

$C_{\max }=\rho_{\max } \Delta z \frac{1000}{\mathrm{MW}_{\mathrm{C}}}$,

where $\rho_{\max }$ is the density of pure organic matter or peat, $\Delta z$ is the soil layer thickness $(\mathrm{m}), \mathrm{MW}_{\mathrm{C}}$ is the molecular weight of carbon $\left(12 \mathrm{~g} \mathrm{~mol}^{-1}\right)$, and the factor of $10^{3} \mathrm{con}-$ verts from grams to kilograms. Based on observations of bulk densities of peat, we assume that $\rho_{\max }$ is $140 \mathrm{~kg} \mathrm{~m}^{-3}$ (Price et al., 2005). The $\mathrm{MW}_{\mathrm{C}}$ term converts the expression into $\mathrm{mol} \mathrm{C} \mathrm{m}{ }^{-2}$, the SiBCASA internal units for carbon. The simulated organic soil fraction per soil layer, $f_{\text {org }}$, is defined as

$f_{\text {org }}=\frac{C}{C_{\max }}$,

where $C$ is the carbon content per soil layer $\left(\mathrm{mol} \mathrm{m}^{-2}\right)$. To convert to carbon we assume that the fraction of organic matter is 0.5 , which means that half of the organic matter by mass is carbon. The original formulation allowed $f_{\text {org }}$ to exceed 1.0 such that the excess organic material was essentially "compressed" into the top soil layer, resulting in a $2 \mathrm{~cm}$ simulated SOL. We place an upper limit of 0.95 on $f_{\text {org }}$ and transfer the excess carbon to the layer below. The OLT is defined as the bottom of the lowest soil layer where $f_{\text {org }}$ is 0.95 .

\subsection{Coupling growth to thaw depth}

We coupled simulated gross primary productivity (GPP), plant phenology, and root growth to simulated thaw depth 

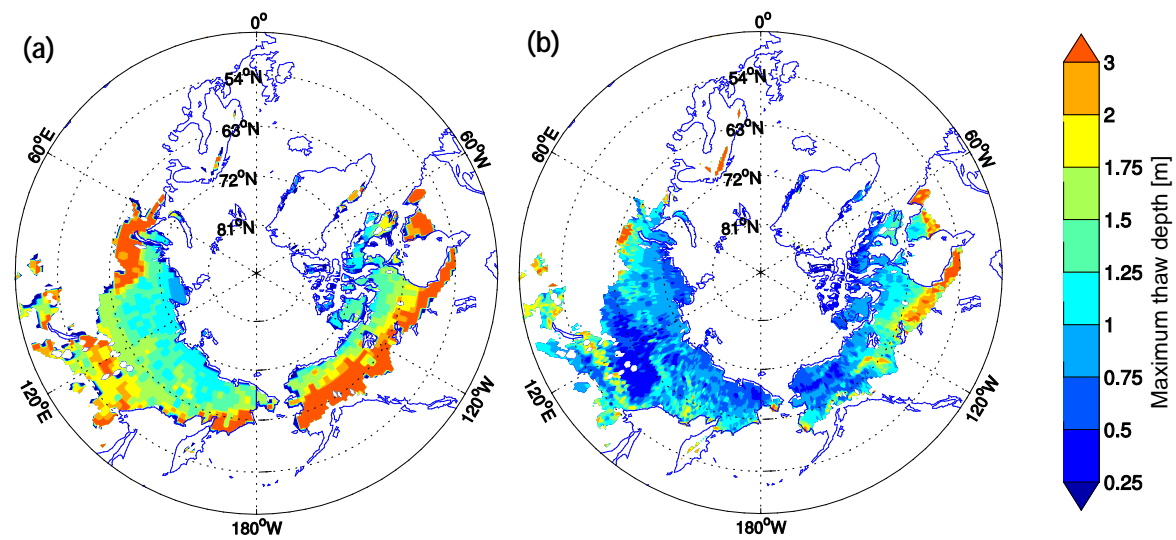

Figure 1. Maximum thaw depth (ALT) averaged over the last 5 years after spin-up from (a) Schaefer et al. (2011) and (b) this study, in meters.

as a function of time. The model assumes that root growth decreases exponentially with depth based on observed vertical root distributions (Jackson et al., 1996; Schaefer et al., 2008). The maximum rooting depth for completely thawed soil is defined as the soil depth corresponding to $99 \%$ of the observed vertical root distribution or $1.1 \mathrm{~m}$ for the tundra and boreal forest biomes. In real life, growing roots cannot penetrate frozen soil (Tryon and Chapin, 1983; Van Cleve et al., 1983), so we restricted simulated root growth to occur only within the thawed portion of the active layer. Typically, the date of snowmelt determines the start date of the growing season (Grøndahl et al., 2007; Wipf and Rixen, 2010). However, in permafrost-affected soils, the start date of the growing season could be delayed by thawing of the active layer. Since fine root and leaf growth are coupled (Schaefer et al., 2008), constraining root growth to thawed soil also constrains spring leaf out to occur after the active layer starts thawing. In real life plants cannot photosynthesize without liquid water in the soil, so we scaled simulated GPP based on the fraction of thawed roots in the root zone.

The previous version of the model distributed fine and coarse root growth vertically within the soil column based on observed root distributions. As the roots died, carbon was transferred to the soil carbon pools for that layer. Thus, the maximum rooting depth determined the maximum depth of "current" or "active" carbon in the model. Of course, if the maximum rooting depth fell below the permafrost table, the model would incorrectly grow roots directly into frozen soil and consequently accumulate permafrost carbon.

In order to restrict simulated root growth to thawed soil layers, we first calculated the fraction of thawed roots within the root zone defined by

$R_{\mathrm{th}}=\sum_{i=1}^{n_{\text {root }}} R_{f_{i}}\left(1-F_{\text {ice }_{i}}\right)$,

where $R_{\mathrm{th}}$ is the fraction of total roots that are thawed, $n_{\text {root }}$ is the soil layer corresponding to the maximum root depth, $R_{f_{i}}$ is the reference root fraction for the $i$ th soil layer based on observed root distributions, and $F_{\text {ice }_{i}}$ is the ice fraction calculated from the simulated ice content for the $i$ th soil layer. When $R_{\text {th }}$ equals 1 , the entire root zone is thawed, and when $R_{\text {th }}$ is zero, the entire root zone is frozen. We assume evenly distributed liquid water in each layer such that $F_{\text {ice }}$ equals the frozen soil fraction. We then calculated $R_{\mathrm{eff}_{i}}$, the effective root fraction for the $i$ th soil layer:

$R_{\text {eff }_{i}}=R_{f_{i}}\left(1-F_{\text {ice }_{i}}\right) / R_{\text {th }}$.

We use $R_{\mathrm{eff}_{i}}$ to distribute new fine and coarse root growth within the soil column. When $R_{\text {eff }_{i}}$ equals zero, the soil layer is frozen with no root growth. Dividing by $R_{\mathrm{th}}$ ensures $R_{\mathrm{eff}}$ sums to 1 within the soil column to conserve mass. This formulation makes the effective maximum rooting depth equal to the thaw depth.

To couple GPP to thaw depth, we treated the reference root zone distribution for completely thawed soil as the maximum root growth capacity defining the maximum potential GPP. When $R_{\mathrm{th}}<1$, the root zone is partially frozen and GPP is less than its full potential. We defined a GPP scaling factor, $S_{\text {soilfrz, as }}$

$S_{\text {soilfrz }}=\left\{\begin{array}{ll}R_{\mathrm{th}} & \text { for } R_{\mathrm{th}} \geq 0.01 \\ 0 & \text { for } R_{\mathrm{th}}<0.01\end{array}\right.$.

This assumes that at least $1 \%$ of the roots must be thawed for GPP to occur, corresponding to about $\sim 1 \mathrm{~cm}$ of thawed soil. $S_{\text {soilfrz }}$ is applied along with the drought stress and temperature scaling factors to constrain photosynthesis (Schaefer et al., 2008). SiBCASA assumes that the factors that control GPP also control wood and leaf growth, so we also included $S_{\text {soilfrz }}$ as a new scaling factor in addition to the drought stress and temperature scaling factors that control wood and leaf growth. 

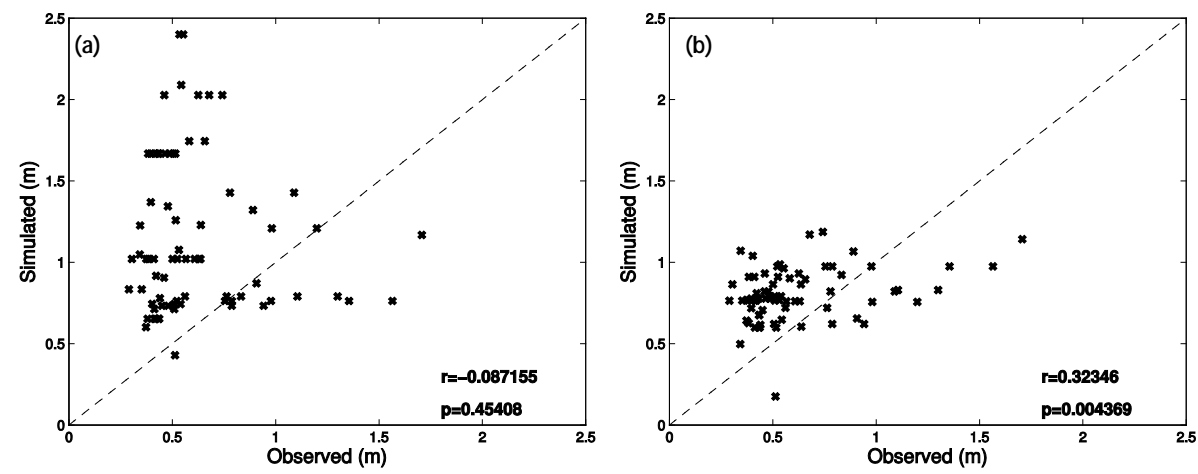

Figure 2. Comparison of ALT from 76 Circumpolar Active Layer Monitoring stations with the averaged ALT from the last 5 years after spin-up from (a) Schaefer et al. (2011) and (b) this study. $r$ is a Pearson's correlation coefficient and $p$ is a significance value; $p<0.05$ stands for the $95 \%$ confidence level.
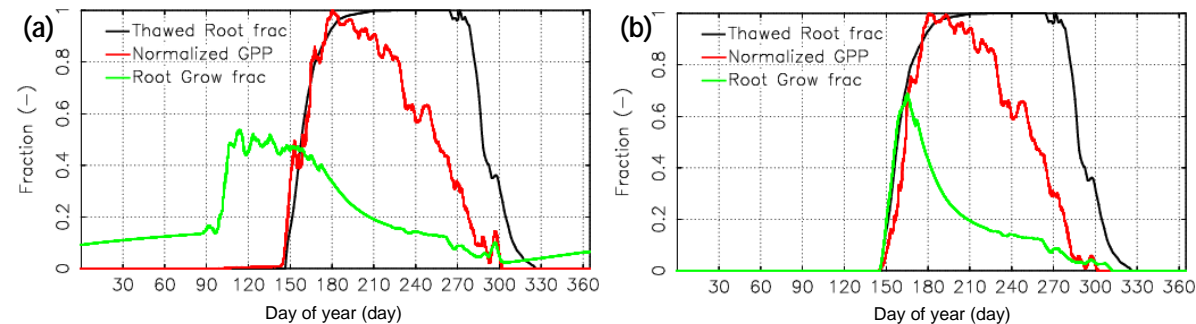

Figure 3. Root growth and GPP without (a) and with (b) the frozen soil constraint on growth. GPP is normalized to a maximum value of 1.0 The root growth fraction is relative to total plant growth.

\section{Results}

The dynamic SOL decreased the simulated ALT on average $50 \%$ across the domain and allowed the model to simulate permafrost in discontinuous zones where it could not before (Fig. 1). The area of near surface permafrost simulated with the current version of the model is equal to $13.5 \mathrm{mil} \mathrm{km}^{2}$, which is almost $38 \%$ greater than without the dynamic SOL (Schaefer et al., 2011). This area is closer to the observed area from the International Permafrost Association: $16.2 \mathrm{mil} \mathrm{km}^{2}$ (Brown et al., 1997). Simulated ALT less than $2 \mathrm{~m}$ covers about $92 \%$ of the area in the new simulations (Fig. 1b) in comparison to $66 \%$ of the area in the Schaefer et al. (2011) simulations (Fig. 1a). The previous version of SiBCASA could not simulate permafrost in many parts of the discontinuous zone with relatively warm climate. Adding the dynamic SOL essentially decreased the thermal conductivity of the surface soil, allowing SiBCASA to simulate permafrost where the mean annual air temperatures are close to $0{ }^{\circ} \mathrm{C}$.

To illustrate the improvement of the simulated ALT with respect to the observed data, we compared simulated ALT with measured values from Circumpolar Active Layer Monitoring (CALM) stations. The CALM network is a part of the Global Terrestrial Network for Permafrost (Burgess et al., 2000). The monitoring network measures ALT either using a mechanical probe or a vertical array of temperature sensors (Brown et al., 2000; Shiklomanov et al., 2010). After matching up the CALM coordinates with the coordinates of previously simulated ALT (Schaefer et al., 2011), we excluded sites with no measurements or ALT greater than $3 \mathrm{~m}$ depth, ending up with 76 CALM stations. Figure 2 shows simulated vs. observed ALT for the 76 CALM sites. The current simulations have a higher resolution than Schaefer et al. (2011) simulations, which allowed us to reach a higher order of heterogeneity between measured and simulated ALTs. The Pearson's correlation coefficient, $R$, is negative and not significant for the Schaefer et al. (2011) simulations (Fig. 2a), but is positive and statistically significant for the current simulations assuming $p<0.05$ (Fig. 2b). The dynamic SOL greatly improves the simulated ALT, but SiBCASA still tends to overestimate ALT.

Figure 3 illustrates the effect of the frozen soil restrictions on phenology and GPP at a single point in central Siberia. Before applying a frozen soil restriction, SiBCASA maintained fine roots even in winter, resulting in root growth all year with a peak in spring corresponding to simulated leaf out (Fig. 3a). Simulated GPP was restricted by liquid water availability and was closely tied to thawing of the active layer, resulting in a lag as high as 60 days between leaf out and start of GPP in spring. Restricting growth and GPP to 

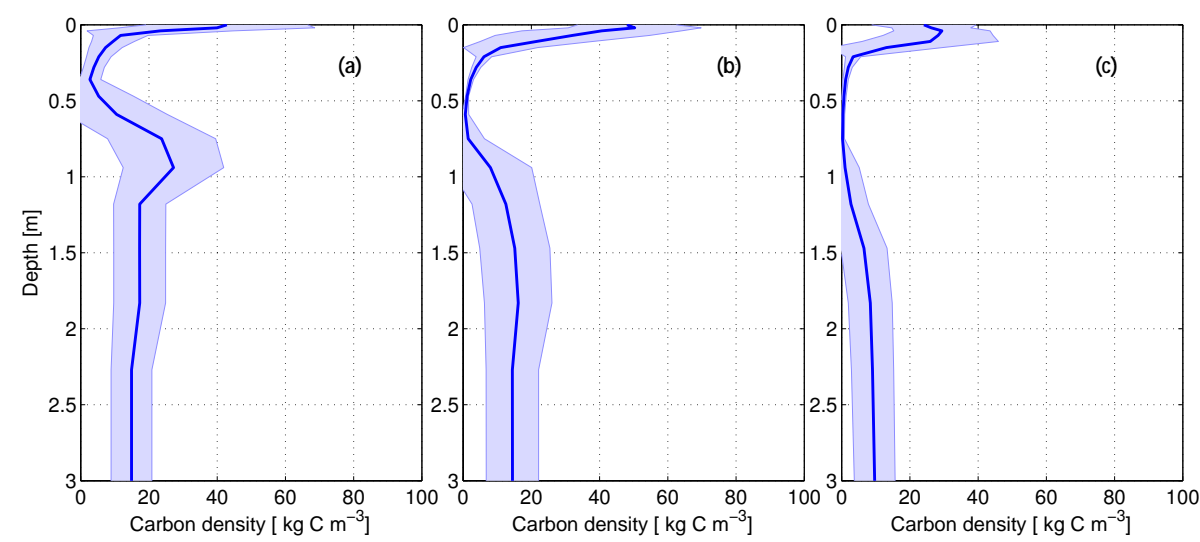

Figure 4. The average soil carbon distribution from 200 grid cells for (a) a tundra region in continuous permafrost zone, (b) boreal forest on the boundary between continuous and discontinuous zones, and (c) low carbon soil at the southern border of the discontinuous permafrost zone. The solid blue curve indicates the mean, and the white blue shading indicates the spread in the simulated soil carbon density.
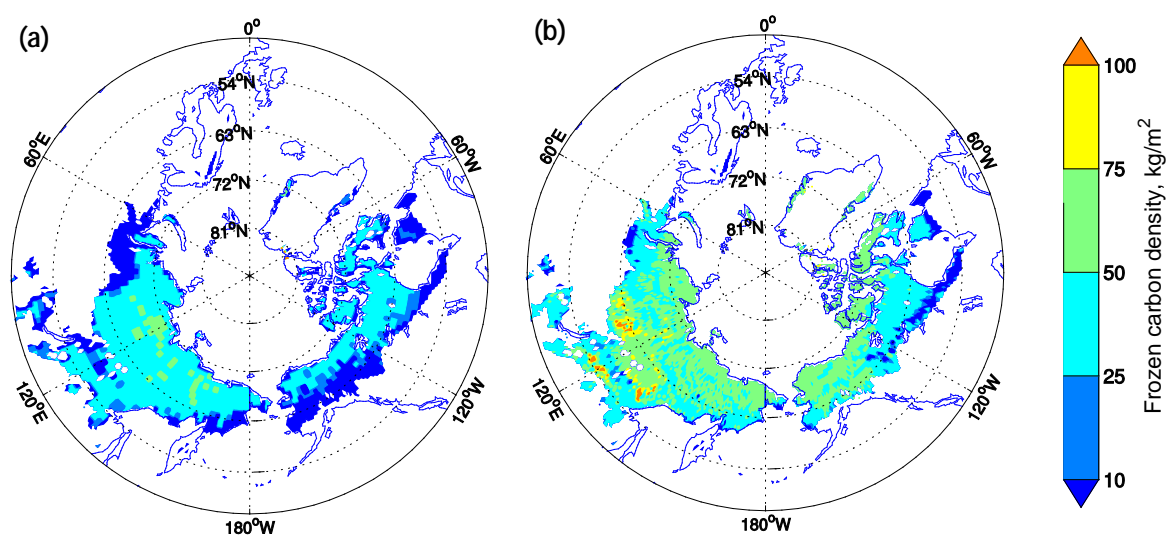

Figure 5. The frozen carbon maps obtained assuming a uniform frozen carbon distribution at the initial time step, and averaged over 5 years at the end of the steady-state run: (a) from Schaefer et al. (2011), and (b) from the current run, correspondingly.

when the soil is thawed essentially synchronizes all phenological events to occur at the same time (Fig. 3b).

Restricting growth and GPP to when the soil is thawed delayed the onset of plant photosynthesis in spring in permafrost-affected regions. Introduction of the thawed root fraction in the model reduced GPP primarily in early spring. To illustrate the difference between unconstrained and restricted root growth (Fig. 3), we ran the model for 10 years for both cases. The difference between unconstrained and restricted root growth resulted in an overall $\sim 9 \%$ reduction in annual GPP for the entire permafrost domain, nearly all of which occurred in spring.

To illustrate soil carbon distribution with depth we selected three representative areas: a continuous permafrost area corresponding to tundra type biome above the Arctic Circle, an area in the boundary of continuous and discontinuous permafrost corresponding to the boreal forest biome, and an area near the south border of the discontinuous permafrost corresponding to poorly vegetated-rocky areas. We calcu- lated the mean and standard deviation of the carbon density distribution with depth for 200 grid points around each of the three selected locations. Simulated typical carbon densities from the selected locations are shown in Fig. 4. All profiles shown in Fig. 4 show a similar pattern: a $20-30 \mathrm{~cm}$ SOL with reduced carbon content at the bottom of the active layer. The SOL and permafrost carbon content matches observed values (Harden et al., 2012), but carbon content near the bottom of the active layer does not, most likely because our model does not include cryoturbation processes.

The decrease in ALT resulting from a dynamic SOL increases the volume of permafrost in the top $3 \mathrm{~m}$ of soil, greatly increasing the initial amount of frozen permafrost carbon in the simulations. Schaefer et al. (2011), without the dynamic SOL, assumed a uniform permafrost carbon density of $21 \mathrm{~kg} \mathrm{C} \mathrm{m}^{-3}$, resulting in a total of $313 \mathrm{Gt}$ of permafrost carbon at the start of their transient run (Fig. 5a). To compare with the results of Schaefer et al. (2011), we initialized the permafrost carbon using the same assumed uniform carbon 

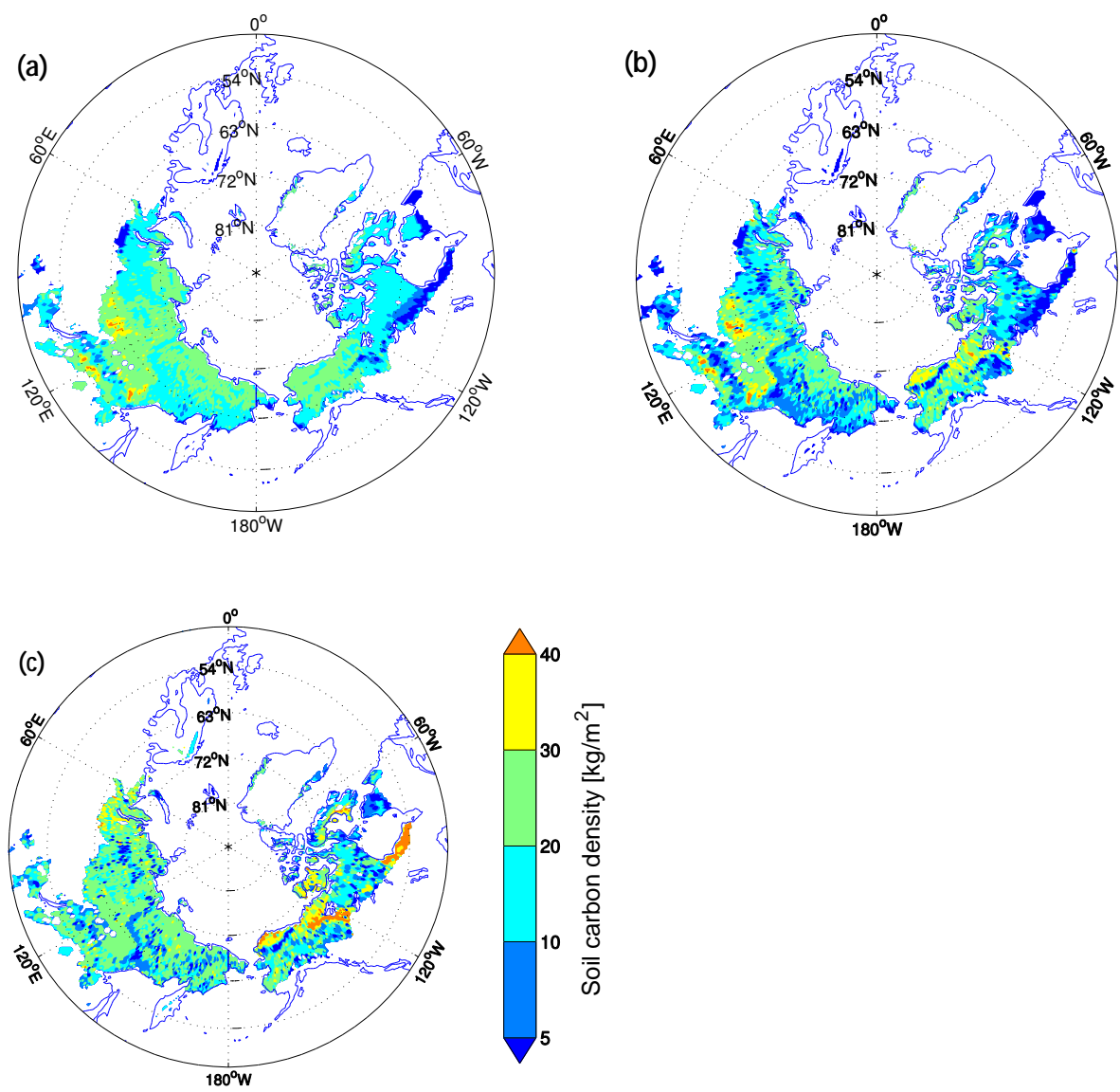

Figure 6. The soil carbon maps averaged over top $3 \mathrm{~m}$ : (a) from SiBCASA at the end of the steady-state run with constant permafrost carbon density, (b) from SiBCASA at the end of the steady-state run with spatially varying permafrost carbon density, and (c) from the NCSCDv2.

density and ran SiBCASA to steady-state initial conditions (Fig. 5b). Assuming the same uniform carbon density, the current version with the dynamic SOL results in a total of $\sim 680 \mathrm{GtC}$ compared to $313 \mathrm{GtC}$ in Schaefer et al. (2011). The dynamic SOL effectively doubled the volume of permafrost in the top $3 \mathrm{~m}$ of soil and the amount of simulated frozen carbon.

Initializing SiBCASA with the observed spatial distribution of permafrost carbon from the NCSCDv2 resulted in $\sim 560 \mathrm{GtC}$ of carbon stored in permafrost after spin-up, close to the observed value $\sim 550 \mathrm{GtC}$ in the top $3 \mathrm{~m}$ of soil (Hugelius et al., 2014). This does not mean that after the spinup-simulated permafrost carbon stocks exactly matched the NCSDCv2 data. In discontinuous zones, for example, if the model simulated permafrost, it tended to produce a deeper ALT and thus less permafrost carbon than the NCSCDv2. Assuming a uniform permafrost carbon density does not account for the spatial heterogeneity in permafrost carbon and overestimates the total amount of permafrost carbon compared to the NCSCDv2 $(680 \mathrm{GtC}$ vs. $550 \mathrm{GtC}$, see Fig. $6 \mathrm{a}$ and $b$ ). The spatial correlation between simulated and observed permafrost carbon is 0.63 when initializing with the
NCSCDv2 (Fig. 6c), compared with a spatial correlation of 0.12 for the uniform permafrost carbon density. The amount and spatial distribution of permafrost carbon significantly improves when initializing with NCSCDv2.

\section{Discussion}

Failure to simulate soil carbon in southeast Canada and southwest Siberia (see Fig. 6b and c) is attributed to deep ALT. These areas correspond to the peat lands. Our model uses the Harmonized World Soil Carbon Database (HWSD) (FAO et al., 2009) to initialize soil texture and related thermal properties. Deep layers of peat have low thermal conductivities, providing an ideal condition for permafrost existence. However, the HWSD does not address peat lands in southeast Canada and southwest Siberia.

The overestimation of soil organic carbon (SOC) in central Siberia results from coupling between GPP and ALT. The dynamic SOL and rooting depth strengthens the feedback between GPP and ALT (Koven et al., 2009). Higher GPP produces greater litter fall, which increases the input soil carbon at the surface and results in a thicker SOL. The dynamic SOL 

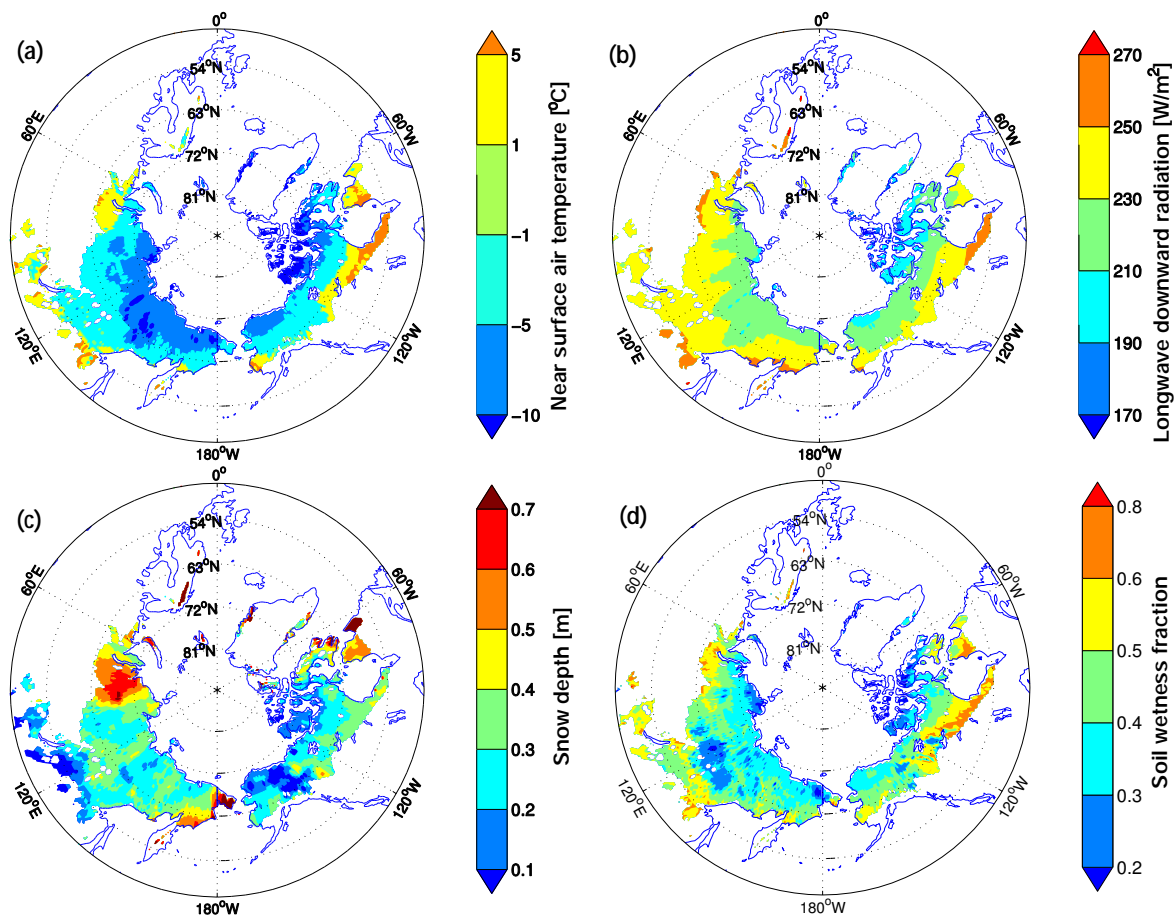

Figure 7. (a) The near-surface air temperature averaged over the first 2 months of the fall season. (b) The downwelling long-wave radiation, averaged yearly over 10 years. (c) The maximum snow depth obtained over 10 years for the steady-state run, and (d) the soil wetness fraction (dimensionless fraction of 1), representing overall near-surface soil wetness, averaged yearly over 10 years.

changes the properties of the near surface soil, resulting in a shallower ALT and cooler soil temperatures. The dynamic rooting depth accounts for a shallower ALT and modulates GPP accordingly. The cooler soil temperatures slow microbial decay and increase the carbon accumulation rate, which in turn increases the SOL and reduces ALT further. Eventually, this feedback results in the development of a peat bog. The changes we describe here indicate that SiBCASA can simulate the dynamics of peat bog development, but the model does not yet include a dynamic vegetation model to account for conversions between biome types, such as boreal forest to peat bog.

The overall amount of permafrost carbon is less than that calculated assuming a uniform frozen carbon distribution. It is important to note that the SOL, ALT, and the permafrost thickness are the same for both cases (Fig. 6a and b). This is due to the fact that in both cases soil carbon is added in the permafrost layer below the active layer. Consequently, the ALT does not change between simulations, and the volume of permafrost in the top $3 \mathrm{~m}$ of soil does not change as well. The smaller permafrost carbon stock simulated for the nonuniform case is mainly due to the fact that we did not initialize frozen carbon in regions where it is not present according to the NCSCDv2, such as the Brooks Range in Alaska.

The dynamic SOL insulates ALT from air temperature, allowing SiBCASA to simulate permafrost in many discontin- uous permafrost regions where it could not before, consistent with previous results where changes in thermal properties associated with the presence of soil organic matter cooled the ground (Lawrence and Slater, 2008; Yi et al., 2009; Ekici et al., 2014; Chadburn et al., 2015a, b). In addition, our work confirms findings by Koven et al. (2009) showing that including SOL dynamics in the model improves agreement with the observed permafrost carbon stocks. However, to better simulate known permafrost distribution in the discontinuous permafrost zone, it is important to know the exact OLT. Unfortunately, in situ measurements of OLT are scarce and essentially lacking in most areas of continuous and discontinuous permafrost.

To investigate the influence of the environmental factors on ALT further, we looked at the relationship between ALT and near surface air temperature (NSAT), soil wetness fraction (SWF), downwelling long-wave radiation (DLWR), and snow depth (SD). The simulated ALT is most influenced by NSAT and soil SWF, with a slightly smaller influence by DLWR, and nonlinearly influenced by SD (Fig. 7). To show the influence of the NSAT, we averaged two early fall months over 10 years. The areas with deep simulated ALT correspond to annual NSAT $>1{ }^{\circ} \mathrm{C}$ in southwest Siberia and NSAT $>5^{\circ} \mathrm{C}$ in southeast Canada with a statistically significant correlation of 0.62 (Fig. 7a). DLWR showed a similar, but slightly weaker relationship with ALT, with higher DLWR values in southeast Canada and southwest Siberia 
and statistically significant correlation of 0.45 (Fig. 7b). Figure $7 \mathrm{c}$ shows maximum simulated snow depth calculated over the last 10 years of the steady-state run. Zhang (2005) indicates that SDs of less than $50 \mathrm{~cm}$ have the greatest impact on soil temperatures. Our results show no correlation between SD and ALT, but the effects of snow on ALT are less obvious and depend on different physical processes, such as wind, snow metamorphism, and depth hoar formation (Sturm et al., 1997; Ekici et al., 2015; Jafarov et al., 2014). We also observe high SWF in southwest Siberia and southeast Canada (see Fig. 7d) where SiBCASA simulates deep ALT with a statistically significant correlation of 0.68 , suggesting that wet soils modulate the insulating effects of the SOL (Lawrence and Slater, 2008). This work does not address the impacts of fire on soil thermodynamics and recovery from fire, both of which are strongly influenced by the changes in the SOL (Jafarov et al., 2013). Studies show that wildfires and climate change could substantially alter soil carbon storage (Yuan et al., 2012; Yi et al., 2010). In the current version of the model the topsoil carbon stays in the system and provides resilience to permafrost. However, in reality, the upper SOL could be removed by fire, which would alter soil thermal properties and perturb permafrost carbon stability.

\section{Conclusion}

This work shows that the dynamic organic layer directly improves the distribution of carbon in soil, as well as indirectly through the improved ALT. Initialization of the carbon according to the NCSCDv2 map allowed us to better match simulated soil carbon with the observed carbon distribution. Restriction of the root growth within the thawed layer prevented artificial accumulation of permafrost carbon. Our model developments improved both the total amount and the spatial distribution of simulated permafrost carbon. The total permafrost carbon increased from 313 to $560 \mathrm{Gt} C$, compared to the observed value of $550 \mathrm{GtC}$, and the spatial correlation with the observed distribution increased from 0.12 to 0.63 . These improvements indicate the importance of including these developments in all land surface models.

In addition, most of the LSMs calculate soil properties based on prognostic soil carbon and soil texture from HWSD. We found that HWSD does not include thermal properties of peat lands, which resulted in inaccurate modeling of the ALT at the southern boundaries of the permafrost domain in Canada and Russia.

Acknowledgements. This research was funded by NOAA grant NA09OAR4310063 and NASA grant NNX10AR63G. This work utilized the Janus supercomputer, which is supported by the National Science Foundation (award number CNS-0821794) and the University of Colorado, Boulder. We thank K. Gregory at NSIDC for reviewing the manuscript. Software tools used in this study include m_map MATLAB package and shadedErrorBar.m
MATLAB script.

Edited by: J. Boike

\section{References}

Ball, J. T.: An analysis of stomatal conductance, Ph.D. thesis, Stanford Univ., Stanford, CA, 1988.

Bonan, G. B.: A Land Surface Model (LSM Version 1.0) for ecological, hydrological, and atmospheric studies: Technical description and users guide, NCAR Tech. Note NCAR/TN-417+STR, Natl. Cent. for Atmos. Res., Boulder, CO, 1996.

Brown, J., Ferrians Jr., O. J., Heginbottom, J. A., and Melnikov, E. S. (Eds.): Circum-Arctic Map of Permafrost and GroundIce Conditions, U.S. Geological Survey in Cooperation with the Circum-Pacific Council for Energy and Mineral Resources, Circum-Pacific Map Series CP-45, scale 1: 10000 000, 1 sheet, 1997.

Brown, J., Hinkel, K.. and Nelson, F.: The 1 Circumpolar Active Layer Monitoring (CALM) program: Research designs and initial results, Polar Geogr., 24, 165-258, doi:10.1080/10889370009377698, 2000.

Burgess, M. M., Smith, S. L., Brown, J., Romanovsky, V., and Hinkel, K.: The Global Terrestrial Network for Permafrost (GTNet-P): Permafrost Monitoring Contributing to Global Climate Observations, available at: http://ftp2.cits.rncan.gc.ca/pub/ geott/ess_pubs/211/211621/cr_2000_e14.pdf (last access: 25 February 2016), 2000.

Callaghan, T. V., Johansson, M., Anisimov, O., Christiansen, H. H., Instanes, A., Romanovsky, V., and Smith, S.: Chapter 5: Changing permafrost and its impacts. In: Snow, Water, Ice and Permafrost in the Arctic (SWIPA) 2011, Arctic Monitoring and Assessment Programme (AMAP), Oslo, 62 pp., 2011.

Chadburn, S., Burke, E., Essery, R., Boike, J., Langer, M., Heikenfeld, M., Cox, P., and Friedlingstein, P.: An improved representation of physical permafrost dynamics in the JULES land-surface model, Geosci. Model Dev., 8, 1493-1508, doi:10.5194/gmd-81493-2015, 2015a.

Chadburn, S. E., Burke, E. J., Essery, R. L. H., Boike, J., Langer, M., Heikenfeld, M., Cox, P. M., and Friedlingstein, P.: Impact of model developments on present and future simulations of permafrost in a global land-surface model, The Cryosphere, 9, 1505-1521, doi:10.5194/tc-9-1505-2015, 2015 b.

Collatz, G. J., Ball, J. T., Grivet, C., and Berry, J. A.: Physiological and environmental regulation of stomatal conductance, photosynthesis, and transpiration: A model that includes a laminar boundary layer, Agr. Forest Meteorol., 54, 107-136, doi:10.1016/0168-1923(91)90002-8, 1991.

Collatz, G. J., Ribascarbo, M., and Berry, J. A.: Coupled photosynthesis-stomatal conductance model for leaves of $\mathrm{C} 4$ plants, Aust. J. Plant Physiol., 19, 519-538, 1992.

Dutta, K., Schuur, E. A. G., Neff, J. C., and Zimov, S. A.: Potential carbon release from permafrost soils of Northeastern Siberia, Global Change Biol., 12, 2336-2351, 2006.

Ekici, A., Beer, C., Hagemann, S., Boike, J., Langer, M., and Hauck, C.: Simulating high-latitude permafrost regions by the JSBACH terrestrial ecosystem model, Geosci. Model Dev., 7, 631-647, doi:10.5194/gmd-7-631-2014, 2014. 
Ekici, A., Chadburn, S., Chaudhary, N., Hajdu, L. H., Marmy, A., Peng, S., Boike, J., Burke, E., Friend, A. D., Hauck, C., Krinner, G., Langer, M., Miller, P. A., and Beer, C.: Site-level model intercomparison of high latitude and high altitude soil thermal dynamics in tundra and barren landscapes, The Cryosphere, 9, 1343-1361, doi:10.5194/tc-9-1343-2015, 2015.

FAO, IIASA, ISRIC, ISS-CAS, and JRC: Harmonized World Soil Database (version 1.1) FAO, Rome, Italy and IIASA, Laxenburg, Austria, 2009.

Farquhar, G. D., von Caemmerer, S., and Berry, J. A.: A biochemical model of photosynthetic $\mathrm{CO}_{2}$ assimilation in leaves of $\mathrm{C} 3$ species, Planta, 149, 78-90, doi:10.1007/BF00386231, 1980.

Grøndahl, L., Friborg, T., and Soegaard, H.: Temperature and snowmelt controls on interannual variability in carbon exchange in the high Arctic, Theor. Appl. Climatol., 88, 111-125, 2007.

Harden, J. W., Koven, C., Ping, C., Hugelius, G., McGuire D. A., Camill, P., Jorgenson, T., Kuhry, P., Michaelson, G. J., O’Donnell, J. A., Schuur, E. A. G., Tarnocai C., Johnson, K., and Grosse, G.: Field information links permafrost carbon to physical vulnerabilities of thawing, Geophys. Res. Lett., 39, L15704, doi:10.1029/2012GL051958, 2012.

Hugelius, G., Tarnocai, C., Broll, G., Canadell, J. G., Kuhry, P., and Swanson, D. K.: The Northern Circumpolar Soil Carbon Database: spatially distributed datasets of soil coverage and soil carbon storage in the northern permafrost regions, Earth Syst. Sci. Data, 5, 3-13, doi:10.5194/essd-5-3-2013, 2013.

Hugelius, G., Strauss, J., Zubrzycki, S., Harden, J. W., Schuur, E. A. G., Ping, C.-L., Schirrmeister, L., Grosse, G., Michaelson, G. J., Koven, C. D., O’Donnell, J. A., Elberling, B., Mishra, U., Camill, P., Yu, Z., Palmtag, J., and Kuhry, P.: Estimated stocks of circumpolar permafrost carbon with quantified uncertainty ranges and identified data gaps, Biogeosciences, 11, 6573-6593, doi:10.5194/bg-11-6573-2014, 2014.

Jackson, R. B., Canadell, J., Ehleringer, J. R., Mooney, H. A., Sala, O. E., and Schulze, E. D.: A global analysis of root distributions for terrestrial biomes, Oecologia, 108, 389-411, doi:10.1007/BF00333714, 1996.

Jafarov, E. E., Marchenko, S. S., and Romanovsky, V. E.: Numerical modeling of permafrost dynamics in Alaska using a high spatial resolution dataset, The Cryosphere, 6, 613-624, doi:10.5194/tc6-613-2012, 2012.

Jafarov, E. E., Romanovsky V. E., Genet, H., McGuire A. D., and Marchenko, S. S.: The effects of fire on the thermal stability of permafrost in lowland and upland black spruce forests of interior Alaska in a changing climate, Environ. Res. Lett., 8, 035030, doi:10.1088/1748-9326/8/3/035030, 2013.

Jafarov, E. E., Nicolsky, D. J., Romanovsky, V. E., Walsh, J. E., Panda, S. K., and Serreze, M. C.: The effect of snow: How to better model ground surface temperatures, Cold Reg. Sci. Technol., 102, 63-77, doi:10.1016/j.coldregions.2014.02.007, 2014.

Johnstone, J. F., Chapin III, F. S., Hollingsworth, T. N., Mack, M. C., Romanovsky, V., and Turetsky, M.: Fire, climate change, and forest resilience in interior Alaska, Can. J. Forest Res., 40, 13021312, 2010.

Koven, C., Friedlingstein, P., Ciais, P., Khvorostyanov, D., Krinner, G., and Tarnocai, C.: On the formation of high-latitude soil carbon stocks: Effects of cryoturbation and insulation by organic matter in a land surface model, Geophys. Res. Lett., 36, L21501, doi:10.1029/2009GL040150, 2009.
Koven, C. D., Ringeval, B., Friedlingstein, P., Ciais, P., Cadule, P., Khvorostyanov, D., Krinner, G., and Tarnocai, C.: Permafrost carbon-climate feedbacks accelerate global warming, P. Natl. Acad. Sci. USA, 108, 14769-14774, doi:10.1073/pnas.1103910108, 2011.

Koven, C. D., Riley, W. J., and Stern, A.: Analysis of permafrost thermal dynamics and response to climate change in the CMIP5 earth system models, J. Climate, 26, 1877-1900, doi:10.1175/JCLI-D-12-00228.1, 2013.

Lawrence, D. M. and Slater, A. G.: Incorporating organic soil into a global climate model, Clim. Dynam., 30, 145-160, doi:10.1007/s00382-007-0278-1, 2008.

MacDougall, A. H., Avis, C. A., and Weaver, A. J.: Significant contribution to climate warming from the permafrost carbon feedback, Nat. Geosci., 5, 719-721, doi:10.1038/NGEO1573, 2012.

Oberman, N. G.: Contemporary Permafrost Degradation of Northern European Russia, in: Proceedings Ninth International Conference on Permafrost, 2, 1305-1310, 2008.

Oleson, K. W., Dai, Y., Bonan, G., Bosilovich, M., Dickinson, R., Feddema, J., Heald, C. L., Hoffman, F., Lamarque, J.-F., Mahowald, N., Niu, G.-Y., Qian, T., Randerson, J., Running, S., Sakaguchi, K., Slater, A., Stöckli, R., Wang, A., Yang, Z. L., Zeng, X., and Zeng, X.: Technical description of the Community Land Model (CLM), NCAR Tech. Note, TN-461+STR, 174 pp., 2004.

Price, J. S., Cagampan, J., and Kellner, E.: Assessment of peat compressibility: is there an easy way?, Hydrol. Process., 19, 34693475, 2005.

Rinke, A., Kuhry, P., and Dethloff, K.: Importance of a soil organic layer for Arctic climate: A sensitivity study with an Arctic RCM, Geophys. Res. Lett., 35, L13709, doi:10.1029/2008GL034052, 2008.

Schaefer, K. and Jafarov, E.: A parameterization of respiration in frozen soils based on substrate availability, Biogeosciences Discuss., 12, 12027-12059, doi:10.5194/bgd-12-12027-2015, 2015.

Schaefer, K., Collatz, G. J., Tans, P., Denning, A. S., Baker, I., Berry, J., Prihodko, L., Suits, N., and Philpott, A.: The combined Simple Biosphere/Carnegie-Ames-Stanford Approach (SiBCASA) Model, J. Geophys. Res., 113, G03034, doi:10.1029/2007JG000603, 2008.

Schaefer, K., Zhang, T., Slater, A. G., Lu, L., Etringer, A., and Baker, I.: Improving simulated soil temperatures and soil freeze/thaw at high-latitude regions in the Simple Biosphere/Carnegie-Ames-Stanford Approach model, J. Geophys. Res., 114, F02021, doi:10.1029/2008JF001125, 2009.

Schaefer, K., Zhang, T., Bruhwiler, and Barrett, A. P.: Amount and timing of permafrost carbon release in response to climate warming, Tellus B, 63, 165-180, doi:10.1111/j.16000889.2011.00527.x, 2011.

Schaefer, K., Lantuit, H., Romanovsky, V. E., Schuur, E. A. G., and Witt, R.: The impact of the permafrost carbon feedback on global climate, Environ. Res. Lett., 9, 085003, doi:10.1088/17489326/9/8/085003, 2014.

Sellers, P. J., Randall, D. A., Collatz, G. J., Berry, J. A., Field, C. B., Dazlich, D. A., Zhang, C., Collelo, G. D., and Bounoua, L.: A Revised Land Surface Parameterization of GCMs, Part I: Model Formulation, J. Climate, 9, 676-705, 1996.

Shiklomanov, N. I., Streletskiy, D. A., Nelson, F. E., Hollister, R. D., Romanovsky, V. E., Tweedie, C. E., Bockheim, J. G., and Brown, J.: Decadal variations of active-layer thickness in moisture- 
controlled landscapes, Barrow, Alaska, J. Geophys. Res., 115, G00I04, doi:10.1029/2009JG001248, 2010.

Schuur, E. A. G., McGuire, A. D., Schädel, C., Grosse, G., Harden, J. W., Hayes, D. J., Hugelius, G., Koven, C. D., Kuhry, P., Lawrence, D. M., Natali, S. M., Olefeldt, D., Romanovsky, V. E., Schaefer, K., Turetsky, M. R., Treat, C. C., and Vonk, J. E.: Climate change and the permafrost carbon feedback, Nature, 520, 171-179, doi:10.1038/nature14338, 2015.

Tarnocai, C., Canadell, J. G., Schuur, E. A. G., Kuhry, P., Mazhitova, G., and Zimov, S.: Soil organic carbon pools in the northern circumpolar permafrost region, Global Biogeochem. Cy., 23, GB2023, doi:10.1029/2008GB003327, 2009.

Tryon, P. and Chapin III, F.: Tem- perature controls over root growth and root biomass in taiga forest trees, Can. J. Forest Res., 13, 827-833, 1983.

Van Cleve, K. L., Oliver, L., Schlentner, R., Viereck, L., and Dyrness, C. T.: Productivity and nutrient cycling in tiaga forest exosystems, Can. J. Forest Res., 13, 747-766, 1983.

Vidale, P. L. and Stockli, R.: Prognostic canopy air space solutions for land surface exchanges, Theor. Appl. Climatol., 80, 245-257, 2005.

Yi, S., Manies, K., Harden, J., and McGuire, A. D.: Characteristics of organic soil in black spruce forests: implications for the application of land surface and ecosystem models in cold regions Geophys. Res. Lett., 36, L05501, doi:10.1029/2008GL037014, 2009.
Yi, S., McGuire, A. D., Kasischke, E., Harden, J., Manies, K. L., Mack, M., and Turetsky, M. R.: A Dynamic organic soil biogeochemical model for simulating the effects of wildfire on soil environmental conditions and carbon dynamics of black spruce forests, J. Geophys. Res., 115, G04015, doi:10.1029/2010JG001302, 2010.

Yuan, F., Yi, S., McGuire, A. D., Johnsen, K. H., Liang, J., Harden, J., Kasischke, E., and Kurz, W.: Assessment of historical boreal forest $\mathrm{C}$ dynamics in Yukon River Basin: Relative roles of warming and fire regime change, Ecol. Appl., 22, 2091-2109, 2012.

Wei, Y., Liu, S., Huntzinger, D. N., Michalak, A. M., Viovy, N., Post, W. M., Schwalm, C. R., Schaefer, K., Jacobson, A. R., Lu, C., Tian, H., Ricciuto, D. M., Cook, R. B., Mao, J., and Shi, X.: The North American Carbon Program Multi-scale Synthesis and Terrestrial Model Intercomparison Project: Part 2 Environmental Driver Data, Geosci. Model Dev., 7, 2875-2893, doi:10.5194/gmd-7-2875-2014, 2014.

Wipf, S. and Rixen, C.: A review of snow manipulation experiments in Arctic and alpine tundra ecosystems, Polar Res., 29, 95-109, doi:10.1111/j.1751-8369.2010.00153.x, 2010.

Zhang, T.: Influence of the seasonal snow cover on the ground thermal regime: An overview, Rev. Geophys., 43, RG4002, doi:10.1029/2004RG000157, 2005. 